\title{
Study on the Gas Film Flow Field and its Influencing Factors at the Outlet of the Orifice of the Aerostatic Bearing
}

\author{
Zhi-Wei Lu (D, Jun-An Zhang, and Bo Liu \\ School of Mechatronic Engineering, Xi'an Technological University, Xi'an 710032, China \\ Correspondence should be addressed to Zhi-Wei Lu; luzhiwei@xatu.edu.cn
}

Received 15 April 2020; Revised 5 September 2020; Accepted 16 October 2020; Published 26 October 2020

Academic Editor: Jin Huang

Copyright (C) 2020 Zhi-Wei Lu et al. This is an open access article distributed under the Creative Commons Attribution License, which permits unrestricted use, distribution, and reproduction in any medium, provided the original work is properly cited.

\begin{abstract}
In order to further explore and study the influencing factors and regulars of the gas film flow field at the outlet of the orifice of the aerostatic bearing, the large eddy simulation method was used to calculate the N-S equation in the calculation area of the gas film flow field at the outlet of the orifice of the aerostatic bearing, and the overrelaxation iteration method was used to solve the Reynolds equation in the other calculation areas, which was proposed in this paper. Based on the physical model of the outlet of the orifice of the aerostatic bearing, the solution area of the gas film flow field of the aerostatic bearing was solved, and the calculation results were analyzed and discussed. The results showed that there was a sharp drop of the gas film pressure at the outlet of the orifice of the aerostatic bearing and the separation of the gas film pressure $p$ became inconsistent in the thickness direction of gas film clearance $h$. It was assumed that there was a critical ratio $\theta$ between the gas film clearance $h$ and the orifice diameter $d$ of the aerostatic bearing, and when the ratio of gas film clearance $h$ to the orifice diameter $d$ was greater than the critical ratio $\theta$, various fluctuations of the gas film flow field began to appear, which may be the initial signal state of the gas film flow field of the aerostatic bearing starting to transition to turbulence. It provided a theoretical basis and guidance for further study of the transition lubrication mechanism between the laminar and the turbulent flow at the outlet of the orifice of the aerostatic bearing in this paper.
\end{abstract}

\section{Introduction}

Aerostatic bearings, with clean and dry air as the lubricating medium, have the advantages of high precision, low friction, no pollution, long service life, good thermal stability, and flexible structure design, which have been widely used in IC manufacturing equipment, precision manufacturing equipment, precision measuring instruments, and other equipment [1-3]. With the requirements of high precision development of submicron and even nanometers in precision and ultraprecision manufacturing and measurement, various factors that have been neglected to affect the performance of aerostatic bearings in the past are gradually being considered and concerned [4-6]. The microvibration of the aerostatic bearing is different from the self-excited vibration of the air hammer during the motion support process. The microvibration is mainly produced by the flow of the internal gas in the aerostatic bearing, whose amplitude is only nanometers to submicrons and frequency is from tens of hertz to thousands of hertz [7]. In the field of precision and ultraprecision manufacturing and measurement, the microvibration has become a technical bottleneck restricting the stability and accuracy improvement of aerostatic bearings. How to better suppress the microvibration of the internal flow field of aerostatic bearings has gradually become one of the hot scientific issues in the research of aerostatic bearings [8-11].

Researchers have studied the performance of the flow field of aerostatic bearings through the theory and the experiment, especially the area of the outlet of the orifice. Mori [12] researched the pressure distribution in the gas film of the parallel disk thrust aerostatic bearing and proposed that there was a sharp pressure drop at the outlet of the orifice of the disk thrust bearing. He found that the pressure distribution in the gas film of the aerostatic bearing did not steadily decrease from the outlet of the orifice to the 
boundary pressure of the aerostatic bearing, and the pressure distribution at the outlet of the orifice no longer followed the Reynolds lubrication equation. Yoshimoto et al. [13] assumed that the flow state of the rising section of the gas film pressure was from the layer to the turbulence. By changing the set value of the gas viscosity and using CFD technology to solve the N-S equation, the pressure distribution near the outlet of the orifice of the aerostatic bearing was obtained, and the calculated pressure value was in good agreement with the experimental value. Eleshaky [14] solved and calculated the Navier-Stokes equation ( $\mathrm{N}-\mathrm{S}$ equation) for the three-dimensional turbulent flow of compressed gas in the circular thrust aerostatic bearing. Under certain conditions, it was found that the pressure drop phenomenon was caused by the interaction between the compression wave and the boundary layer and produced microvibration. Miyatake and Yoshimoto [15] obtained the flow coefficient by comparing the results of CFD simulation and the results of solving the Reynolds equation by FDM, then obtained the gas film pressure distribution of the thrust aerostatic bearing by solving the Reynolds equation, and found that the thrust aerostatic bearing with small orifice had a large damping and stiffness coefficient. Chen and He [16] found cyclones in the flow field near the orifice outlet through CFD simulation of ring throttle and orifice throttle of aerostatic bearings and put forward the view that the cyclones cause the microvibration of aerostatic bearings earlier in the world. Aoyama et al. [17] also observed cyclones in the flow field behind the orifices of the small orifice restrictor in subsequent studies and reduced the intensity of cyclones and the microvibration of aerostatic bearings by changing the right-angle connection at the junction of the orifices and the gas cavity into the fillet connection. Chen et al. [18] proposed a novel design of an arrayed microhole restrictor which suppressed the vortex flow and reduced vibration of aerostatic bearings, and the air vortex flow can induce small amplitude vibration of aerostatic bearings on the order of nanometers. Zhu et al. [19] wanted to capture turbulent structures and fluctuations; and the LES method was employed to numerically calculate the transient flow field in the bearing clearance, and they proposed that the quantity analysis of the relationship between pressure fluctuation and small vibration of aerostatic bearings was needed in the future work.

Through the research of a large number of scholars, it was found that the traditional aerostatic bearing had relatively low requirements for accuracy, and the focus of the research was mainly on how to improve the macromechanical properties of the aerostatic bearing, such as the bearing capacity and the bearing stiffness, rarely from the analysis and research of the internal gas flow state of the aerostatic bearing $[8,20-22]$. However, with the continuous improvement of the precision requirements of the ultraprecision motion platform supported by the gas flotation, the vibration magnitude caused by the gas flow pattern in the gas film flow field was close to the motion precision of the platform, which had become a bottleneck hindering the development of the ultraprecision motion platform supported by the gas flotation in the future. In order to further explore and study the influencing factors and regulars of the film flow field at the outlet of the orifice of aerostatic bearings, the large eddy simulation method was used to calculate the $\mathrm{N}-\mathrm{S}$ equation in the calculation area of the gas film flow field at the outlet of the orifice of aerostatic bearings, and the overrelaxation iteration method was used to solve the Reynolds equation in the other calculation areas, which was proposed in this paper. The factors that affected the stability of the gas film flow field were discussed, and the bearing capacity of the aerostatic bearing was tested. The research and analysis of the gas film flow field at the outlet of the orifice of aerostatic bearings had an important research and guiding significance for further improving the application and promotion of the gas lubrication support technology in precision and ultraprecision motion mechanisms and instruments in this paper.

\section{Physical Model and the Governing Equation}

2.1. Physical Model. The aerostatic bearing is a kind of the static pressure bearing which uses the high-pressure gas as the moving lubricating medium, whose physical model is shown in Figure 1. The high-pressure gas is supplied from the external air source equipment. After purification, pressure regulation, and pressure stabilization, the highpressure gas enters the orifice of the aerostatic bearing through the gas passage for the gas supply of the body of the aerostatic bearing, then enters the gas film clearance between the two supporting moving parts (the body of the aerostatic bearing and the bearing part of the guide), and produces the supporting and lubricating gas film to support and balance external load. When the aerostatic bearing works, the two moving parts are always filled with high-pressure lubricating gas to ensure no direct contact. Therefore, the aerostatic bearing has good characteristics of no friction and wear, high precision, high speed, no pollution, and good thermal stability.

In order to explore and study the gas film flow field of aerostatic bearings, the aerostatic bearing shown in Figure 1 is taken as the research object in this paper. In Figure 1, the physical model of the aerostatic bearing is expressed as follows: $\varphi D$ is the overall diameter of the aerostatic bearing, and $H$ is the overall height of the aerostatic bearing. The part of area $A$ shown by a red dotted line at the outlet of the orifice of the aerostatic bearing in Figure 1 is studied emphatically in this paper. Its internal geometric parameters are as follows: $\varphi d$ is the diameter of the orifice, $l$ is the length of the orifice, $h$ is the gas film clearance of the flow field, and $\varphi D 1$ is the diameter of the dotted line selected in the calculation area of the flow field.

2.2. Governing Equation. The fluid motion in the gas film clearance between the aerostatic bearing and the bearing part of the guide should meet the three laws of conservation of mass, momentum, and energy, including the continuity equation, momentum equation, and energy equation, and the N-S equation of its Cartesian tensor expression are formulas (1)-(3), respectively [23]. 


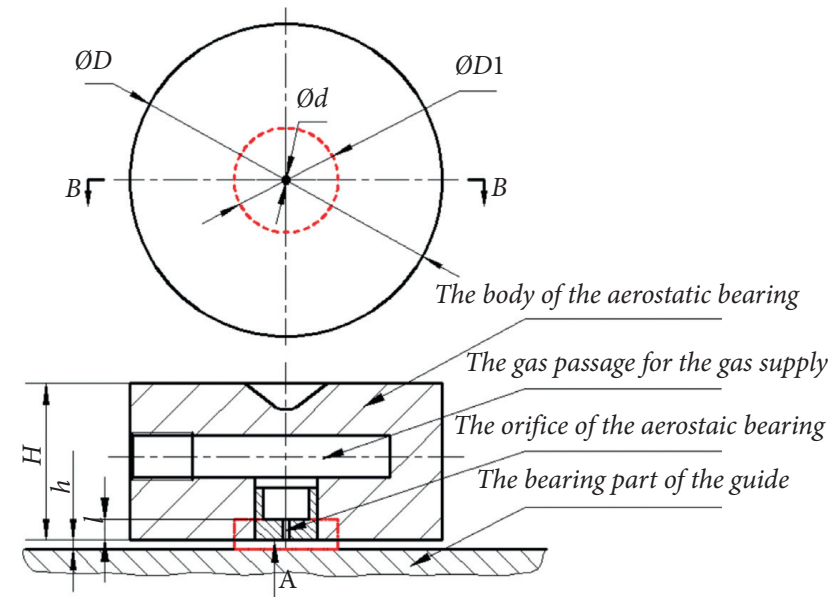

'FIgURE 1: Sketch map of the physical model of the aerostatic bearing.

$$
\begin{gathered}
\frac{\partial \rho}{\partial t}+\frac{\partial \rho u_{j}}{\partial x_{j}}=0, \\
\frac{\partial \rho u_{i}}{\partial t}+\frac{\partial \rho u_{i} u_{j}}{\partial x_{j}}=-\frac{\partial p}{\partial x_{i}}+\frac{\partial \sigma_{i j}}{\partial x_{j}}, \\
\frac{\partial \rho E}{\partial t}+\frac{\partial \rho u_{i} E}{\partial x_{i}}=-\frac{\partial p u_{i}}{\partial x_{i}}+\frac{\partial u_{i} \sigma_{i j}}{\partial x_{j}}-\frac{\partial q_{i}}{\partial x_{i}},
\end{gathered}
$$

where $\rho$ is the gas density; $t$ is the time; $u_{i}$ and $u_{j}$ are the velocity components in the direction of $i$ and $j$ in Cartesian coordinates, respectively; $x_{i}$ and $x_{j}$ are the coordinates in the direction of $i$ and $j$; $\sigma_{i j}$ is the element (component) of viscous stress tensor; the subscript $i$ is the normal direction of action surface; the subscript $j$ is the projection direction of force; $E$ is the total internal energy of unit mass fluid; $p$ is the gas film pressure of flow field; and $q_{i}$ is the heat flux density of heat conduction.

The method of the large eddy simulation (LES) is used to solve the flow field at the outlet of the orifice for the lubrication fluid of the aerostatic bearing studied in this paper. The governing equations of the large eddy simulation are equations (4)-(6) after the density weighted filtration of equations (1)-(3). The density and the pressure are represented by the superscript " " for physical space filtering, and the speed, the temperature, and the internal energy are represented by the superscript “-” for the density weighted filtering.

$$
\begin{aligned}
\frac{\partial \widetilde{\rho}}{\partial t}+\frac{\partial \widetilde{\rho} \bar{u}_{j}}{\partial x_{j}}= & 0, \\
\frac{\partial \widetilde{\rho} \bar{u}_{i}}{\partial t}+\frac{\partial\left(\widetilde{\rho} \bar{u}_{i} \bar{u}_{j}\right)}{\partial x_{j}}= & -\frac{\partial \widetilde{p}}{\partial x_{i}}+\frac{\partial \bar{\sigma}_{i j}}{\partial x_{j}}+\frac{\partial\left(\widetilde{\rho}\left(\bar{u}_{i} \bar{u}_{j}-\bar{u}_{i} u_{j}\right)\right)}{\partial x_{j}} \\
& +\frac{\partial\left(\widetilde{\sigma}_{i j}-\bar{\sigma}_{i j}\right)}{\partial x_{j}},
\end{aligned}
$$

$$
\frac{\partial \widetilde{\rho} \bar{E}}{\partial t}+\frac{\partial \widetilde{\rho} \bar{u}_{i} \bar{E}}{\partial x_{i}}=-\frac{\partial \widetilde{p} \bar{u}_{i}}{\partial x_{i}}+\frac{\partial \bar{u}_{i} \bar{\sigma}_{i j}}{\partial x_{j}}-\frac{\partial \bar{q}_{i}}{\partial x_{i}}+\bar{A}
$$

In equation (5), two additional terms are produced after the filtration, both of which are related to sublattice pulsation, where $\tilde{\rho}\left(\bar{u}_{i} \bar{u}_{j}-\overline{u_{i} u_{j}}\right)$ is the sublattice stress term, and $\bar{\sigma}_{i j}$ is the molecular viscous stress with filtration speed and temperature as parameters; in equation (6), $\bar{A}$ represents multiple additional sublattice mode terms that need to be added.

When the gas film flow field in the aerostatic bearing works at low speed, the relative sliding velocity between aerostatic bearings is very small compared with the velocity generated by the gas pressure, so the lubricating fluid can be considered as two-dimensional steady compressible fluid. The flow field of the circular aerostatic bearing is studied in this paper. In order to ensure the grid division, numerical convergence, and stability, the numerical calculation of the circular aerostatic bearing is more appropriate and reasonable in the polar coordinate system. Gas lubrication control equation (7) in the polar coordinate system is derived and simplified by equations (1)-(3).

$$
\frac{\partial^{2} p^{2}}{\partial r^{2}}+\frac{1}{r^{2}} \frac{\partial^{2} p^{2}}{\partial \theta^{2}}+\frac{1}{r} \frac{\partial p^{2}}{\partial r}+\frac{3}{h} \frac{\partial h}{\partial r} \frac{\partial p^{2}}{\partial r}+\frac{3}{h r^{2}} \frac{\partial h}{\partial \theta} \frac{\partial p^{2}}{\partial \theta}=0
$$

where $h$ is the gas film clearance, $r$ is the polar radius in the polar coordinate system, and $\theta$ is the polar angle in the polar coordinate system.

According to the theory of the fluid lubrication, it can be obtained that, during the calculation process, the fluid flow in the gas film clearance and the fluid flow at the orifice of the aerostatic bearing should be kept in the balance, and equation (8) of the flow balance equation must be satisfied.

$$
Q_{\text {in }}=Q_{\text {out }} \text {. }
$$

In equation (8), $Q_{\text {in }}$ is the flow of gas through the orifice of the aerostatic bearing into the gas film clearance, and its expression is as follows:

$$
Q_{\text {in }}=\frac{A C_{0} \Psi p_{s}}{\sqrt{R T_{0}}}
$$

where in formula (9),

$$
\begin{aligned}
& \Psi=\left(\frac{2 \kappa}{\kappa-1}\left(\left(\frac{p_{0}}{p_{s}}\right)^{2 / \kappa}-\left(\frac{p_{0}}{p_{s}}\right)^{\kappa+1 / \kappa}\right)\right)^{1 / 2}, \quad \frac{p_{0}}{p_{s}} \geq\left(\frac{2}{\kappa+1}\right)^{\kappa / \kappa-1}, \\
& \Psi=\left(\frac{2 \kappa}{\kappa+1}\left(\frac{2}{\kappa+1}\right)^{2 / \kappa-1}\right)^{1 / 2}, \quad \frac{p_{0}}{p_{s}}<\left(\frac{2}{\kappa+1}\right)^{\kappa / \kappa-1},
\end{aligned}
$$

where $A$ is the area of the orifice, $C_{0}$ is the coefficient of the nozzle flow, $p_{0}$ is the pressure at the outlet of the orifice, $p_{s}$ is the gas supply pressure, $T_{0}$ is the gas supply temperature, and $\kappa$ is the gas insulation coefficient.

$Q_{\text {out }}$ is the flow of gas from the gas film clearance of the aerostatic bearing into the surrounding environment. The 
formula of $Q_{\text {out }}$ of the aerostatic bearing studied in this paper is

$$
Q_{\text {out }}=\frac{\rho h^{3}}{12 \mu} \int_{0}^{2 \pi} \frac{\partial p}{\partial r} r d \theta
$$

where $\rho$ is the density of the gas and $\mu$ is the dynamic viscosity of the gas.

According to gas lubrication control equation (7) and flow balance equation (8), the pressure distribution in the gas film clearance can be solved, and the static performance of the bearing capacity $W$ and the stiffness $K$ of the aerostatic bearing can be obtained.

2.3. Calculation Method and Boundary Conditions. The pressure distribution still follows the simplified Reynolds lubrication equation (7) in the gas film clearance of the aerostatic bearing outside the region of the outlet of the orifice. However, due to the pressure drop phenomenon in the gas film flow field, the pressure distribution near the outlet of the orifice of the aerostatic bearing no longer follows the Reynolds lubrication equation [12]. Due to the limitation of computational resources, the large eddy simulation (LES) method [24] is proposed to solve the numerical value of governing equations (4)-(6) in the flow field near the orifice of the aerostatic bearing (within the diameter $\varphi D 1$ of part A of the dotted line box in Figure 1) in this paper. Simplified Reynolds equation (7) is solved by the overrelaxation iteration method in other regions (outside the diameter $\varphi D 1$ of part A of the dotted line box in Figure 1). The dotted box A of the gas film flow field in Figure 1 is selected as the research object in this paper, and the section in the calculation physical model is obtained along section B-B in Figure 1, as shown in Figure 2. In Figure 2, (1) is the inlet of the high pressure gas flow field of the orifice, (2) is the wall surface of the orifice, (3) is the upper wall surface of the gas film flow field, (4) is the outlet of the gas film flow field, and (5) is the lower wall surface of the gas film flow field.

There are three types of boundary conditions in the flow field solution area studied in this paper: the inlet boundary condition, the wall boundary condition, and the outlet boundary condition, which are, respectively, as follows: (1) the inlet boundary condition: the inlet of (1) is the flow field inlet boundary in Figure 2, and the inlet pressure is $p=p_{s}$, where $p_{s}$ is the inlet gas supply pressure; (2) the wall boundary condition: walls of (2), (3), and (5) are set to adopt the nonsliding wall boundary conditions, i.e., $u=0, v=0$, and the wall equal temperature is $T=T_{w}$, where $T_{w}$ is the wall temperature; (3) the outlet boundary condition: the outlet of (4) is set as the outlet boundary of the flow field, and the pressure of its outlet is $p=p_{1}$, where $p_{1}$ is the outlet interface pressure of the flow field, and the pressure $p_{1}$ value at the outlet of the flow field boundary is determined by the numerical calculation of Reynolds equation (7) and the flow balance equation (8).

2.4. Grid Division. The aerostatic bearing with $\varphi D=30 \mathrm{~mm}$ and $H=15 \mathrm{~mm}$ (see Figure 1) is selected as the research object in this paper. According to the complex flow field within the diameter of $\varphi D 1$ in part A of the dotted box in Figure 1, the grid of convection field is specifically divided as shown in Figure 3. Figure 3(a) is the grid division of the flow field within the diameter of $\varphi D 1$ in part $\mathrm{A}$ of the dotted box in Figure 1, all of which are divided by the three-dimensional structure grid, and the encrypted grid is used for the grid division of the wall of the orifice and the wall of the gas film clearance; Figure 3(b) is the partial enlarged grid at the intersection of the orifice and the gas film clearance at $\mathrm{E}$ in Figure 3(a).

In order to analyze and express the flow field in the solution area more clearly and accurately, the $y=0$ section of the flow field solution region is obtained along section $\mathrm{B}-\mathrm{B}$ in Figure 1 and section B-B in the area of the outlet of orifice in Figure 2(a), as shown in Figure 4(a). In Figure 4(a), combined with the size of the model in Figure 1, the internal geometry parameters are set: the diameter $\varphi d$ of the orifice ranges from $0.05 \mathrm{~mm}$ to $0.2 \mathrm{~mm}$, the length $l$ of the orifice is $0.3 \mathrm{~mm}$, the value of the gas film clearance $h$ in the flow field ranges from $5 \mu \mathrm{m}$ to $20 \mu \mathrm{m}$, and the diameter $\varphi D 1$ of the dotted line in the flow field calculation area is $8 \mathrm{~mm}$. The solution area of the gas film flow field in Figure 4(a) is divided into two large areas for the grid division: the flow field region of the orifice and the flow field region of the gas film clearance. The grid division of the flow field region of the orifice is $100 \times(60 \sim 120) \times(60 \sim 120)$, in which $(60 \sim 120)$ is set according to the size of the orifice diameter $\varphi d$. The grid division of the flow field region of the gas film clearance is divided into $800 \times(60 \sim 120) \times(30 \sim 90)$, in which $(30 \sim 90)$ is set according to the size of the flow field. The $x$-direction (radial direction) and $z$-direction (gas film thickness direction) grids are nonequidistant structural grids. Because the accuracy of LES is very sensitive to the resolution of the mesh, a more refined mesh should be generated in the outlet region of the orifice until the refinement of the mesh can ensure the significant change of the calculation results. The grids are encrypted when the grids are close to the wall surface, where the longitudinal grid spacing $\Delta z 1$ of each first layer along the $z$-direction from the upper wall (3) and the lower wall (5) (as shown in Figure 2) is taken as $0.05 \mu \mathrm{m}$, and the horizontal grid spacing $\Delta x 1$ of the first layer along the $x$ direction wall (2) (as shown in Figure 2) is taken as $0.2 \mu \mathrm{m}$, as shown in Figure 4(b) (Figure 4(b) is the partial enlarged grid at $\mathrm{C}$ in Figure 4(a)). The grid division is treated by the structural grid by trying to compare in this paper. The results show that the average number of hexahedral meshes in the whole region of the film flow field of various types of aerostatic bearings is between $1.4 \times 10^{6}$ and $8.0 \times 10^{6}$, the minimum grid volume is $0.01 \mu \mathrm{m}^{3}$, the maximum grid volume is $350 \mu \mathrm{m}^{3}$, and the dimensionless $y^{+}$ranges from 0.4 to 0.7 . Dimensionless $y^{+}$reflects the resolution of the grid near the wall, which is defined as $y^{+}=\sqrt{\rho \tau_{w}} y / \mu$, where $y$ is the distance between the grid center of the first adjacent wall and the wall and $\tau_{w}$ is the wall shear stress. In order to accurately solve the flow field of the boundary layer near the wall, the mesh refinement is used to ensure that it is always less than 1 .

In order to facilitate the following accurate description and expression of the parameters in the flow field, three cross 


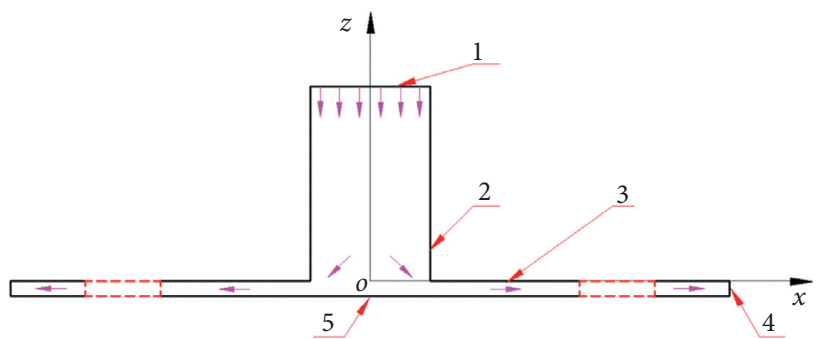

FIGURE 2: Sketch map of the cross section of the physical model for calculation of the gas film flow field.

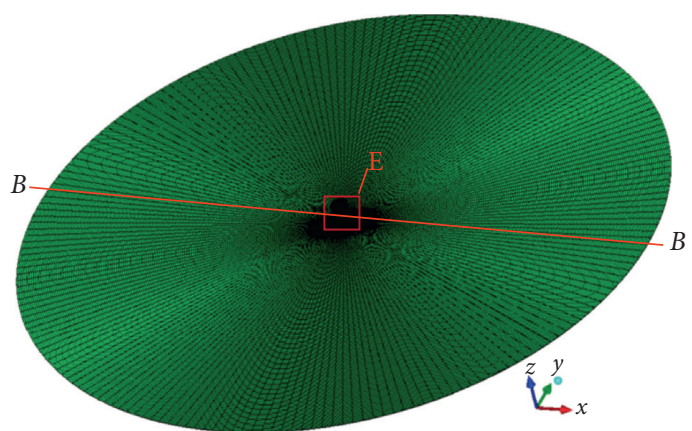

(a)

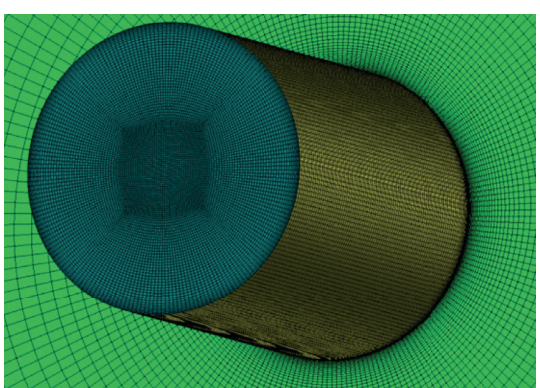

(b)

Figure 3: Schematic diagram of the grid division of the outlet of the orifice. (a) Grid division of area A of the dotted box; (b) local magnification of grids at E.

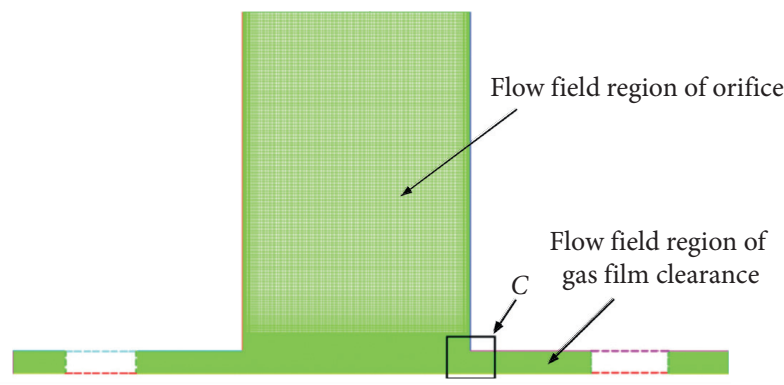

(a)

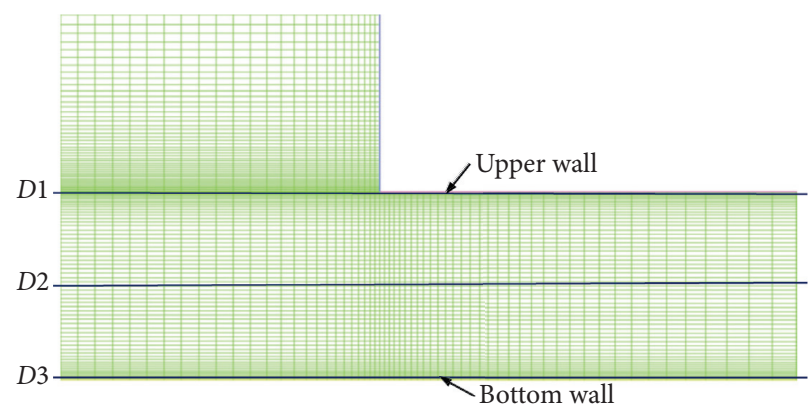

(b)

FIgURE 4: Schematic diagram of the area division for the outlet of the orifice. (a) Grid division; (b) local magnification of grid at C.

sections $D 1, D 2$, and $D 3$ are taken along the $z$-direction (the gas film thickness direction) in the flow field area of the gas film clearance. The cross section line $D 1$ is adjacent to the first grid line of the upper wall (3), the cross section line $D 2$ is the middle grid line of the middle section of the gas film clearance of the flow field area, and the cross section line D3 is adjacent to the first grid line of the lower wall (5) layer gridlines.

\section{Calculation Results and Analysis}

3.1. Influence Parameters of the Bearing Capacity and the Gas Mass Flow. The circular aerostatic bearing with the diameter $D=30 \mathrm{~mm}$ is selected as the research object, and the physical model is shown in Figure 1. The influence parameters of the supply pressure $p_{s}$, the gas film clearance $h$, and the diameter $d$ of the orifice on the lubrication mechanism of the aerostatic bearing are studied in this paper. The governing equation (7) is discretized by the finite difference method, and the flow balance equation (8) and related boundary conditions are solved by using the overrelaxation iteration method. Assuming that the gas is normal temperature gas, the environment pressure $p_{a}=0.1 \mathrm{MPa}$, the gas constant $R=287 \mathrm{~J} /(\mathrm{kg} \cdot \mathrm{K})$, the gas supply temperature $T_{0}=288 \mathrm{~K}$, the gas insulation coefficient $\kappa=1.4$, the coefficient of the nozzle $C_{0}=0.85$, the dynamic viscosity of the gas $\mu=1.883 \times 10^{-5} \mathrm{~N} \cdot \mathrm{s} / \mathrm{m}^{2}$, and the density of the gas $\rho=1.226 \mathrm{~kg} / \mathrm{m}^{2}$. When the gas supply pressure $p_{s}$ is $0.4 \mathrm{MPa}$, the orifice diameter $d$ of the aerostatic bearing is $0.08 \mathrm{~mm}$, $0.16 \mathrm{~mm}$, and $0.20 \mathrm{~mm}$, respectively; when the orifice diameter $d$ is $0.20 \mathrm{~mm}$, the gas supply pressure $p_{s}$ of the aerostatic bearing is $0.4 \mathrm{MPa}, 0.5 \mathrm{MPa}$, and $0.6 \mathrm{MPa}$, respectively; the gas film clearance $h$ of the aerostatic bearing is selected from $3 \mu \mathrm{m}$ to $20 \mu \mathrm{m}$. The influence factors of the 
bearing capacity $W$ and the gas mass flow $Q$ of aerostatic bearings are analyzed under different gas supply pressures $p_{s}$ and orifice diameter $d$ in this paper. The curves of the calculation results of the bearing capacity $W$ and the gas mass flow $Q$ under different influence parameters are shown in Figures 5 and 6.

Figure 5 shows the change of the bearing capacity $W$ and the gas film clearance $h$ of the aerostatic bearing under different gas supply pressures $p_{s}$ and different orifice diameter $d$. It can be seen from Figure 5 that the bearing capacity $W$ of the aerostatic bearing decreases with the increase of the gas film clearance $h$ on the whole; under the condition that the orifice diameter $d$ of the aerostatic bearing does not change, the higher the gas supply pressure $p_{s}$ is, the greater the bearing capacity $W$ is; when the gas supply pressure $p_{s}$ of the aerostatic bearing is the same, the maximum bearing capacity of the aerostatic bearing in a different orifice diameter $d$ is basically the same, and the bearing capacity $W$ of the aerostatic bearing decreases with the increase of gas film clearance $h$, and the larger the orifice diameter $d$ is, the greater the bearing capacity $W$ is under the same gas film clearance $h$, but its overall bearing stiffness is relatively smaller.

Figure 6 shows the change of the gas mass flow $Q$ and the gas film clearance $h$ of the aerostatic bearing under different gas supply pressures $p_{s}$ and different orifice diameter $d$. It can be seen from Figure 6 that the gas mass flow $Q$ of the aerostatic bearing increases gradually with the increase of gas film clearance $h$ on the whole; when the orifice diameter $d$ or the supply pressure $p_{s}$ are the same, the gas mass flow $Q$ of the aerostatic bearing increases with the increase of the gas supply pressure $p_{s}$ or the orifice diameter $d$.

\subsection{Influence Parameter of the Gas Supply Pressure of Aero-} static Bearings. In order to discuss and study the gas film flow field of the physical model at the outlet area of the orifice of the aerostatic bearing in Figure 2, the physical model in Figure 1 has been selected as the research object of the aerostatic bearing with the diameter $D=30 \mathrm{~mm}$ in this paper. The specific internal geometric parameters are as follows: the diameter $D 1$ of the research calculation area of the outlet of the orifice is $8 \mathrm{~mm}$, the selection range of the diameter $d$ of the orifice is from $0.05 \mathrm{~mm}$ to $0.2 \mathrm{~mm}$, the length $l$ of the orifice is $0.3 \mathrm{~mm}$, the selection range of the gas film clearance $h$ is from $5 \mu \mathrm{m}$ to $20 \mu \mathrm{m}$, and the selection range of the gas supply pressure $p_{s}$ is from $0.4 \mathrm{MPa}$ to $0.6 \mathrm{MPa}$. The flow field curves of grid lines $D 1, D 2$, and $D 3$ in Figure 4(b) are selected as the representative for the flow field for analysis and research. Due to the symmetry of the calculation physical model of the outlet area of the orifice of the aerostatic bearing in Figure 2, in order to express more conveniently and concisely, only the $O_{x}$ positive direction area on the right side of the $O_{z}$ axis is selected for research and analysis in the later discussion.

The gas supply pressure $p_{s}$ of the aerostatic bearing is analyzed and researched on the flow field in the outlet area of the orifice. When other boundary conditions and parameters of the calculation area at the outlet of the orifice of the aerostatic bearing remain unchanged, the gas film clearance $h$ of the aerostatic bearing is set to $20 \mu \mathrm{m}$ and the diameter $d$ of the orifice is set to $0.2 \mathrm{~mm}$. When the gas supply pressure $p_{s}$ at the inlet of the flow field is set to $0.4 \mathrm{MPa}, 0.5 \mathrm{MPa}$, and $0.6 \mathrm{MPa}$, respectively, the flow field at the outlet of the orifice is analyzed and studied. The calculation results of the flow field are shown in Figures 7 and 8.

Figure 7 shows the pressure distribution of the curves $D 1, D 2$, and $D 3$ at the outlet of the orifice of aerostatic bearings at the gas film clearance $h=20 \mu \mathrm{m}$ and under different gas supply pressures $p_{s}$. It can be seen from Figure 7 that the pressure $p$ of each curve shows a rapid and steep drop and the curve $D 1$ shows the most obvious steep drop at the junction of the outlet of the orifice and the gas film clearance (i.e., $x=d / 2=0.10 \mathrm{~mm}$ ). The larger the gas supply pressure $p_{s}$ is, the larger the sharp drop of pressure $p$ is. The sharp drop of pressure $p$ of the curves $D 2$ and $D 3$ is a little to the right of the outlet of the orifice and the gas film clearance, but it is not as large as the curve D1. Under the condition of different gas supply pressures $p_{s}$, the pressure $p$ of the curves $D 1, D 2$, and $D 3$ shows separation and begins to fluctuate up and down to a certain extent, in which the fluctuation amplitude of $p_{s}=0.4 \mathrm{MPa}$ is the smallest and $p_{s}=0.6 \mathrm{MPa}$ is the largest, until the pressure $p$ of the curves $D 1, D 2$, and $D 3$ near $x=0.45 \mathrm{~mm}$ remerges and becomes stable. From the change of each pressure curve in Figure 7, it can be seen that the gas film pressure $p$ of the flow field is separated and becomes inconsistent in the thickness direction of the gas film clearance $h$ near the outlet of the orifice, which further explains that it is not appropriate to use the Reynolds equation to solve the numerical value of the gas film flow field area at the outlet of the orifice. However, it is feasible to use the Reynolds equation to solve the film flow field far away from the outlet of the orifice after the pressure $p$ recombines and stabilizes.

Figure 8 shows the velocity $V$ distribution of the curves $D 1, D 2$, and $D 3$ at the outlet of the orifice of aerostatic bearings at the gas film clearance $h=20 \mu \mathrm{m}$ and under different gas supply pressures $p_{s}$. It can be seen from Figure 8 that the velocity $V$ value of each curve shows a rapid and sharp rise and the curve $D 2$ is the most obvious at the junction of the outlet of the orifice and the gas film clearance (i.e., $x=d / 2=0.10 \mathrm{~mm}$ ). The larger the gas supply pressure $p_{s}$ is, the steeper the velocity $V$ is. The velocity $V$ of the curves $D 1$ and $D 3$ also have the steeper rise phenomenon, whereas the steeper rise is smaller than that of the curve $D 2$. The main reason is that the curves $D 1$ and $D 3$ are adjacent to the upper and lower walls of the gas film clearance, respectively, and the viscous resistance of the gas film wall boundary layer has a greater impact on them. In the case of different gas supply pressures $p_{s}$, the velocity $V$ of each curve $D 2$ increases with the gradual deviation from the junction of the outlet of the orifice and the gas film clearance (i.e., $x=d /$ $2=0.10 \mathrm{~mm}$ ) and, then, gradually decreases and fluctuates up and down to a certain extent, in which the fluctuation of $p_{s}=0.4 \mathrm{MPa}$ is the smallest, the fluctuation of $p_{s}=0.6 \mathrm{MPa}$ is the largest, and the fluctuation range is wider until the velocity $V v$ near $x=0.45 \mathrm{~mm}$ tends to be stable. When the gas supply pressure $p_{s}$ of the aerostatic bearing studied is 


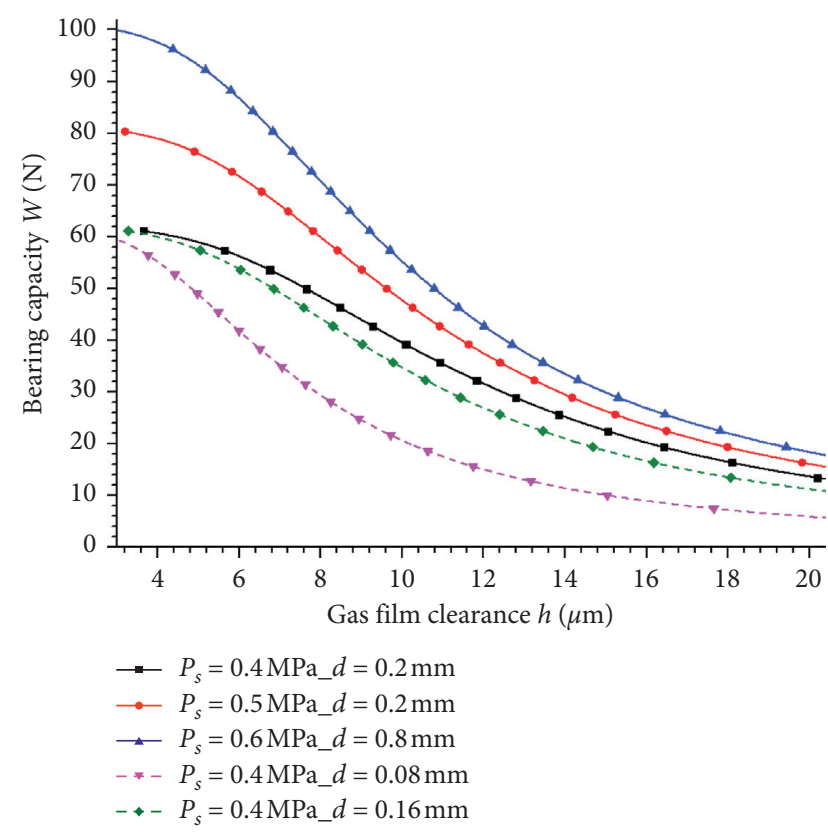

FIgURE 5: Change curve of bearing capacity.

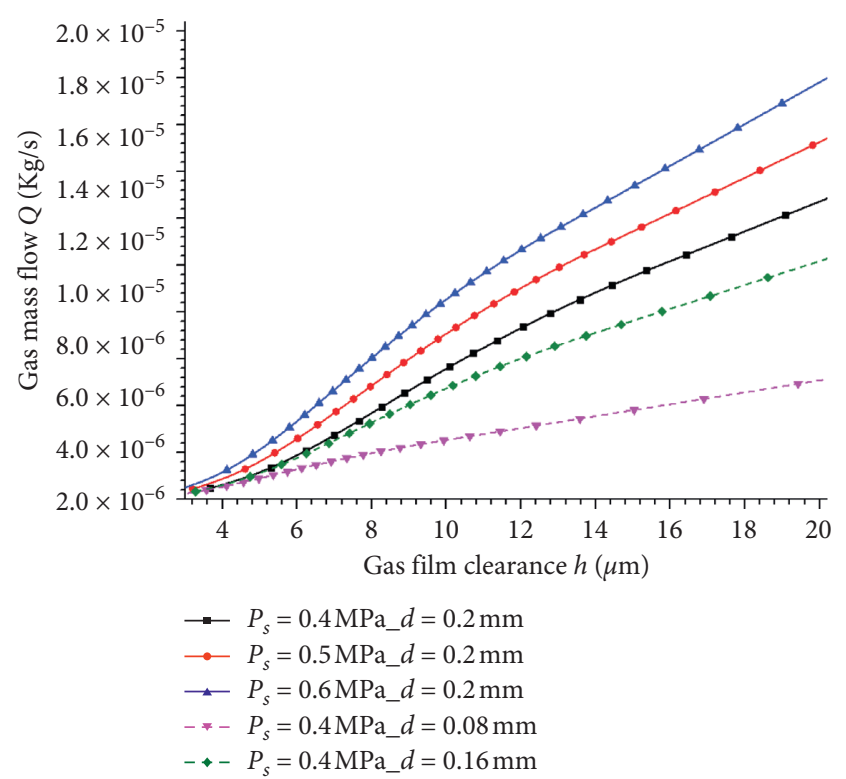

FIgURE 6: Change curve of gas mass flow under different influence parameters under different influence parameters.

$0.4 \mathrm{MPa}, 0.5 \mathrm{MPa}$, and $0.6 \mathrm{MPa}$, respectively, in this paper, the cloud chart of the velocity $V$ of the gas film flow field at the outlet of the orifice of the aerostatic bearing is as shown in Figure 9. The unit of the horizontal ordinate in Figure 9 is meters, and the unit of the velocity of the cloud chart in Figure 9 is meters per second.

It can also be seen from Figures 7-9 that the change trend of the $D 1$ curve is more significant for the change trend of the gas film pressure $P$ at the outlet of the orifice of the aerostatic bearing, and the curve $D 2$ is more significant for the change trend of the velocity $V$ of the gas film flow field.

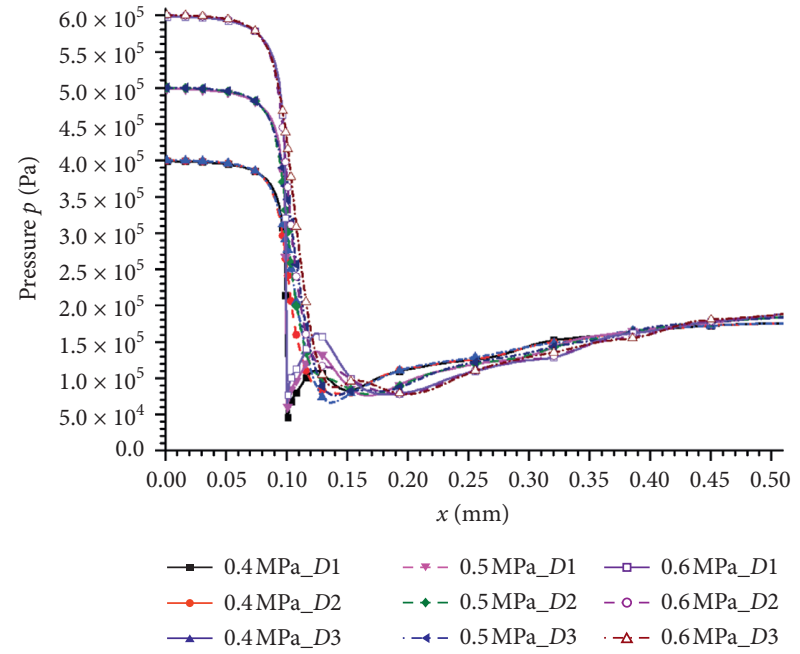

Figure 7: Curves of the pressure of the gas film at different $p_{s}$.

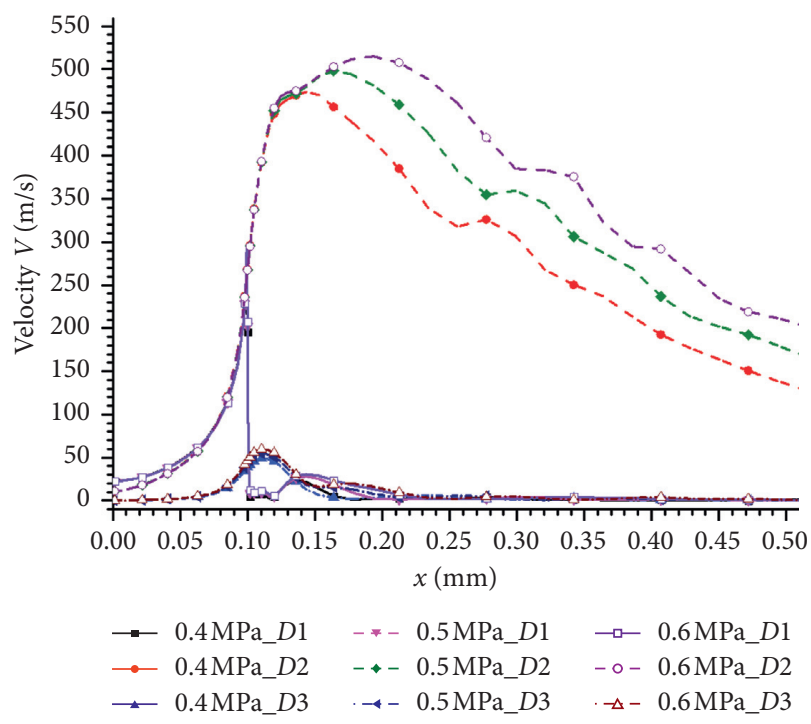

Figure 8: Curves of the velocity of the gas film at different $p_{s}$.

Therefore, in the later part of this paper, for the research and analysis of the film flow field of the aerostatic bearing, the curve $D 1$ is selected to represent the pressure $p$ change of the gas film flow field, and the curve $D 2$ is selected to represent the velocity $V$ change of the gas film flow field.

3.3. Influence Parameter of the Gas Film Clearance of the Aerostatic Bearing. The gas film clearance $h$ of the aerostatic bearing is analyzed and researched on the flow field in the outlet area of the orifice. When other boundary conditions and parameters of the calculation area at the outlet of the orifice of the aerostatic bearing remain unchanged, the inlet gas supply pressure $p_{s}$ of the aerostatic bearing is set to $0.4 \mathrm{MPa}$ and the diameter $d$ of the orifice is taken as two sizes 


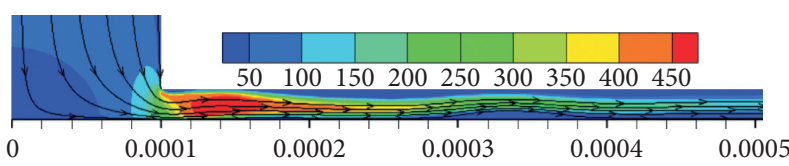

(a)

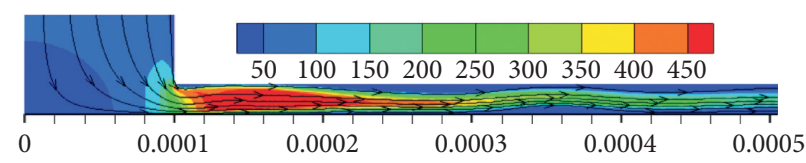

(b)

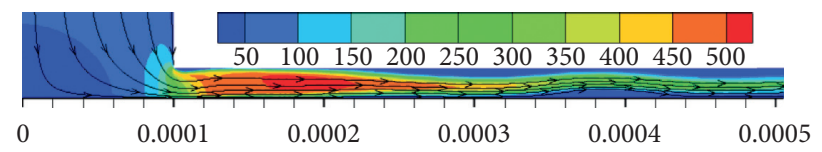

(c)

Figure 9: Cloud chart of the velocity of the gas film at different $p_{s}$. (a) $p_{s}=0.4 \mathrm{MPa}$, (b) $p_{s}=0.5 \mathrm{MPa}$, and (c) $p_{s}=0.6 \mathrm{MPa}$.

$d=0.08 \mathrm{~mm}$ and $d=0.16 \mathrm{~mm}$, respectively. When the gas film clearance $h$ of the flow field is taken as $6 \mu \mathrm{m}, 8 \mu \mathrm{m}$, $10 \mu \mathrm{m}, 12 \mu \mathrm{m}, 16 \mu \mathrm{m}$, and $20 \mu \mathrm{m}$, respectively, the large eddy simulation (LES) method is used to analyze and study the flow field at the outlet of the orifice. The calculation results of the gas film clearance $h$ of the aerostatic bearing on the gas film flow field are shown in Figures 10 and 11.

Figure 10 shows the pressure distribution of the curve D1 at the outlet of the orifice of aerostatic bearing, which is under the gas supply pressure $p_{s}=0.4 \mathrm{MPa}$ and the different gas film clearance $h$ of the aerostatic bearing. It can be seen from Figure 10 that the pressure $p$ of each curve $D 1$ drops rapidly and negative pressure appears under many gas film clearances $h$, which is at the junction of the outlet of the orifice and the gas film clearance (i.e., $x=d / 2=0.04 \mathrm{~mm}$ and $x=d / 2=0.08 \mathrm{~mm}$ ). The larger the gas film clearance $h$ is, the larger the drop amplitude of the pressure $p$ is and the more obvious the negative pressure phenomenon is. Under the same gas film clearance $h$, the drop of the pressure of the gas film flow field with the diameter $d=0.08 \mathrm{~mm}$ of the orifice is larger than that with the diameter $d=0.16 \mathrm{~mm}$ of the orifice. The pressure $p$ of each curve $D 1$ drops sharply and, then, rises again. For the gas film flow field with diameter $d=0.08 \mathrm{~mm}$, when the gas film clearance $h$ is less than or equal to $8 \mu \mathrm{m}$, the pressure curve $D 1$ rises very smoothly. But, when the gas film clearance $h$ is greater than $8 \mu \mathrm{m}$, the pressure curve $D 1$ rises gradually with a certain fluctuation, and the larger the gas film clearance $h$ is, the larger the amplitude and the range of its fluctuation are. For the gas film flow field with the diameter $d=0.16 \mathrm{~mm}$, when the gas film clearance $h$ is less than $16 \mu \mathrm{m}$, the pressure of the curve $D 1$ rise is relatively stable. But, when the gas film clearance $h$ is greater than or equal to $16 \mu \mathrm{m}$, the pressure of the curve $D 1$ rises and gradually appears a certain fluctuation, and the larger the gas film clearance $h$ is, the larger the amplitude and the range of its fluctuation are.

Figure 11 shows the velocity $V$ of the curve $D 2$ at the outlet of the orifice of the aerostatic bearing, which is under the gas supply pressure $p_{s}=0.4 \mathrm{MPa}$ and a different gas film clearance $h$ of aerostatic bearing. It can be seen from Figure 11 that the velocity $V$ of each curve $D 2$ shows a rapid and steep rise, which is near the junction of the outlet of the orifice and the gas film clearance (i.e., $x=d / 2=0.04 \mathrm{~mm}$ and $x=d / 2=0.08 \mathrm{~mm}$ ). The larger the gas film clearance $h$ is, the larger the sharp rise of the velocity $V$ is, and the position with the sharp rise deviates from the position at the junction of the outlet of the orifice and the gas film clearance. Under the same gas film clearance $h$, the rise in amplitude of the velocity of the gas film flow field with the diameter $d=0.08 \mathrm{~mm}$ of the orifice is larger than that with the diameter $d=0.16 \mathrm{~mm}$ of the orifice. The velocity $V$ of each curve $D 2$ increases sharply and, then, decreases. When the gas film clearance $h$ is less than or equal to $8 \mu \mathrm{m}$, with the diameter $d=0.08 \mathrm{~mm}$ of the gas film flow field, the velocity of the curve D2 decreases very smoothly. However, the gas film clearance $h$ is greater than $8 \mu \mathrm{m}$, and the velocity of the curve $D 2$ gradually fluctuates up and down to a certain extent. The larger the gas film clearance $h$ is, the larger the amplitude and the range of their fluctuation are.

When the gas film clearance $h$ is less than $16 \mu \mathrm{m}$, for the gas film flow field with diameter $d=0.16 \mathrm{~mm}$, the velocity of the curve D2 rises steadily. But, the gas film clearance $h$ is greater than or equal to $16 \mu \mathrm{m}$, and the velocity of the curve D2 declines gradually to a certain extent. The larger the gas film clearance $h$ is, the larger the amplitude and the range of their fluctuation are. The larger the amplitude and the range of the velocity fluctuation of the gas film flow field are, the greater the influence on the stability of the precision mechanism is. It can be seen from the analysis of the results in Figures 10 and 11 that the correlation between the gas film pressure $p$ and the gas film velocity $V$ at the same working condition and location of the gas film flow field is quite obvious, which also shows the feasibility of this large eddy simulation (LES) calculation method and the correctness of the results. When the inlet gas supply pressure $p_{s}$ of the aerostatic bearing studied is $0.4 \mathrm{MPa}$, the diameter $d$ of the orifice is $d=0.08 \mathrm{~mm}$ and $d=0.16 \mathrm{~mm}$, and the gas film clearance $h$ is $6 \mu \mathrm{m}, 8 \mu \mathrm{m}, 10 \mu \mathrm{m}, 12 \mu \mathrm{m}, 16 \mu \mathrm{m}$, and $20 \mu \mathrm{m}$, respectively; the cloud chart of the velocity $V$ of the gas film flow field in the calculation area at the outlet of the orifice of the aerostatic bearing is shown in Figure 12. The unit of the horizontal ordinate in Figure 12 is meters, and the unit of the velocity of the cloud chart in Figure 12 is meters per second.

3.4. Influence Parameter of the Diameter of the Orifice of the Aerostatic Bearing. The diameter $d$ of the orifice of the aerostatic bearing is analyzed and researched on the flow field in the outlet area of the orifice. When other boundary conditions and parameters of the calculation area at the 


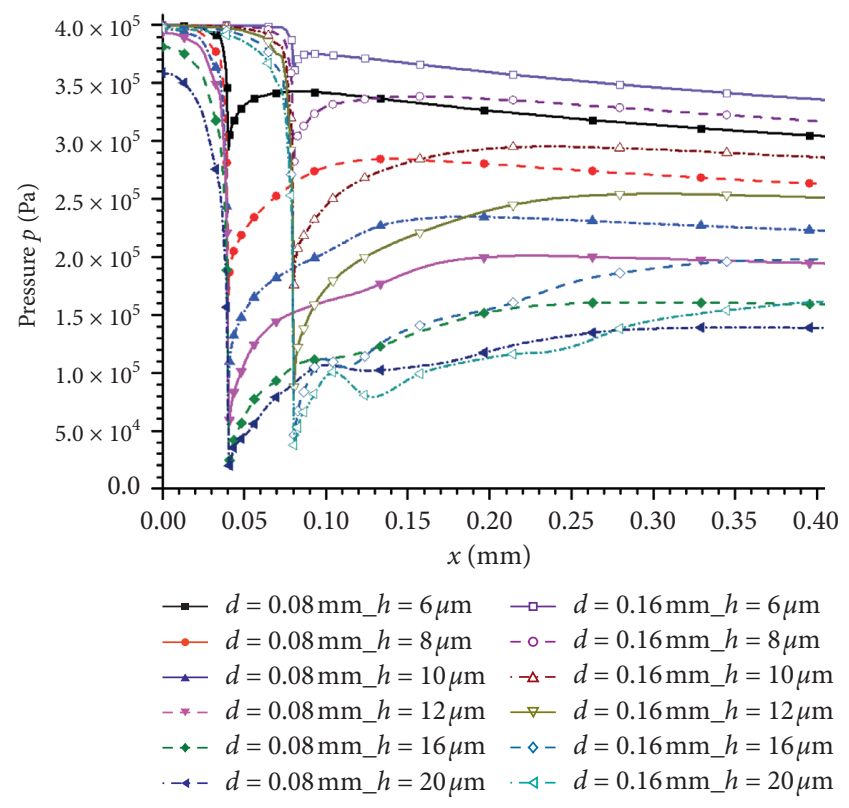

Figure 10: Curves D1 of the pressure of the gas film at different $h$.

outlet of the orifice of the aerostatic bearing remain unchanged, the inlet gas supply pressure $p_{s}$ of the aerostatic bearing is set to $0.4 \mathrm{MPa}$, the gas film clearance $h$ of the aerostatic bearing is taken as two sizes $h=8 \mu \mathrm{m}$ and $h=0.16 \mu \mathrm{m}$, respectively, and the diameter $d$ of the orifice of the flow field is taken as $0.06 \mathrm{~mm}, 0.08 \mathrm{~mm}, 0.10 \mathrm{~mm}$, $0.12 \mathrm{~mm}, 0.16 \mathrm{~mm}$, and $0.20 \mathrm{~mm}$, respectively. With the gas film clearance $h$ of the flow field taken as $6 \mu \mathrm{m}, 8 \mu \mathrm{m}, 10 \mu \mathrm{m}$, $12 \mu \mathrm{m}, 16 \mu \mathrm{m}$, and $20 \mu \mathrm{m}$, respectively, the large eddy simulation (LES) method is used to analyze and study the flow field at the outlet of the orifice. The calculation results of the diameter $d$ of the orifice of the aerostatic bearing on the gas film flow field are shown in Figures 13 and 14.

Figure 13 shows the pressure distribution of the curve $D 1$ at the outlet of the orifice of the aerostatic bearing, which is at the gas film clearance $h$ of $8 \mu \mathrm{m}$ and $0.16 \mu \mathrm{m}$, respectively, and under the different diameter $d$ of the orifice. It can be seen from Figure 13 that the pressure $p$ of each curve $D 1$ drops rapidly at the corresponding junction of the outlet of the orifice and the gas film clearance (i.e., $x=d / 2=0.03 \mathrm{~mm}$, $0.04 \mathrm{~mm}, 0.05 \mathrm{~mm}, 0.06 \mathrm{~mm}, 0.08 \mathrm{~mm}$, and $0.10 \mathrm{~mm}$ ). The pressure curve $D 1$ of the gas film clearance $h=16 \mu \mathrm{m}$ has a larger steeper drop than the pressure curve $D 1$ of the gas film clearance $h=8 \mu \mathrm{m}$, which shows that the gas film clearance $h$ has a significant and positive effect on the pressure drop at the outlet of the orifice. In the case of the same gas film clearance $h$, the sharp drop of the pressure $p$ at the outlet of the orifice of the aerostatic bearing decreases with the increase of the diameter $d$ of the orifice. The film flow field increases gradually after the drop of the pressure at the outlet of the orifice. When the gas film clearance $h$ is $8 \mu \mathrm{m}$, the increase of most of the pressure curves $D 1$ are stable and smooth (only pressure curve $D 1$ with the orifice diameter $d=0.06 \mathrm{~mm}$ shows slight fluctuation rise), and the smaller the diameter $d$ of the orifice is, the smaller the overall pressure value is. When the gas film clearance $h$ is $16 \mu \mathrm{m}$, the

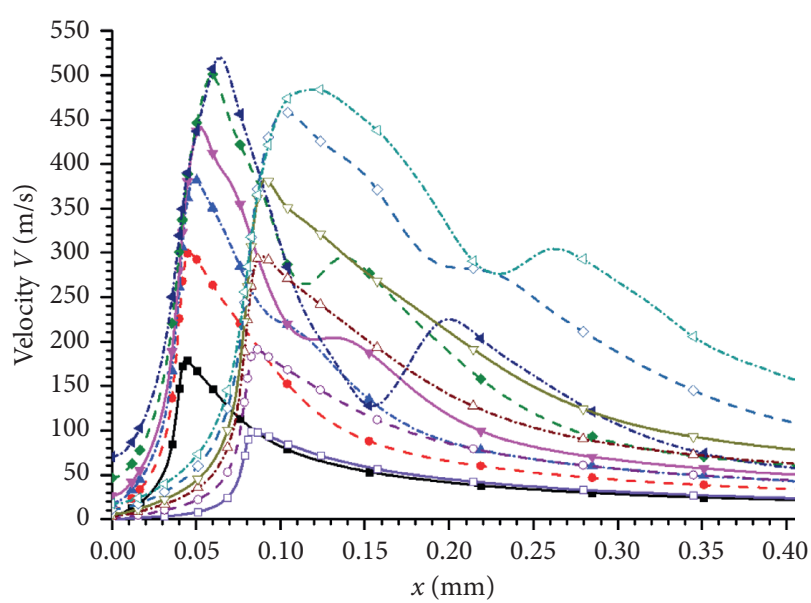

$$
\begin{aligned}
& \longrightarrow d=0.08 \mathrm{~mm} \_h=6 \mu \mathrm{m} \quad \longrightarrow-d=0.16 \mathrm{~mm} \_h=6 \mu \mathrm{m} \\
& \therefore d=0.08 \mathrm{~mm} \_h=8 \mu \mathrm{m} \quad-\circ-d=0.16 \mathrm{~mm} \_h=8 \mu \mathrm{m} \\
& \multimap d=0.08 \mathrm{~mm} \_h=10 \mu \mathrm{m} \cdot \Delta-d=0.16 \mathrm{~mm} \_h=10 \mu \mathrm{m} \\
& -\neq-d=0.08 \mathrm{~mm} \_h=12 \mu \mathrm{m} \rightarrow d=0.16 \mathrm{~mm} \_h=12 \mu \mathrm{m} \\
& -\bullet d=0.08 \mathrm{~mm} \_h=16 \mu \mathrm{m}-\diamond-d=0.16 \mathrm{~mm} \_h=16 \mu \mathrm{m} \\
& -4 d=0.08 \mathrm{~mm} \_h=20 \mu \mathrm{m} \cdot \triangleleft-d=0.16 \mathrm{~mm} \_h=20 \mu \mathrm{m}
\end{aligned}
$$

Figure 11: Curves D2 of the velocity of the gas film at different $h$.

pressure of the curve $D 1$ will fluctuate in different degrees, and the smaller the diameter $d$ of the orifice is, the more obvious the fluctuation amplitude of the overall pressure will be.

Figure 14 shows the velocity distribution of the curve $D 2$ at the outlet of the orifice, which is at the gas supply pressure $p_{s}=0.4 \mathrm{MPa}$ and under the different diameter $d$ of the orifice of the aerostatic bearing. It can be seen from Figure 14 that the velocity $V$ of each curve $D 2$ of the gas film flow field, which is near the junction of the outlet of the orifice and the gas film clearance (i.e., $x=d / 2=0.03 \mathrm{~mm}, 0.04 \mathrm{~mm}$, $0.05 \mathrm{~mm}, 0.06 \mathrm{~mm}, 0.08 \mathrm{~mm}$, and $0.10 \mathrm{~mm}$ ), shows a rapid and steep rise phenomenon. The larger the gas film clearance $h$ is, the larger the sharp rise of velocity $V$ is, and the position of the sharp rise is more deviated from the position of the junction between the outlet of the orifice and the gas film clearance. At the same gas film clearance $h$, the velocity of the curve $D 2$ of the gas film flow field increases rapidly with the decrease of the diameter $d$ of the orifice of the aerostatic bearing. The curves $D 2$ of each velocity rise sharply at the outlet of the orifice, and then, the velocity values fall again. When the gas film clearance is $8 \mu \mathrm{m}$, most of the curves $D 2$ of the velocity decrease steadily and smoothly, and the smaller the diameter $d$ of the orifice is, the smaller the overall velocity value is. Only the velocity of the curve $D 2$ with the diameter $d=0.06 \mathrm{~mm}$ of the orifice fluctuates slightly in the process of the descent. When the gas film clearance $h$ is $16 \mu \mathrm{m}$, the increase of the velocity of the curve $D 2$ will fluctuate in different degrees. The smaller the diameter $d$ of the orifice is, the larger the fluctuation amplitude of the overall pressure will be. The larger the diameter $d$ of the orifice is, the smaller the fluctuation amplitude of the overall pressure value will be, but the larger the fluctuation range will be. When the gas supply pressure $p_{s}$ is $0.4 \mathrm{MPa}$, the gas film clearance $h$ is $8 \mu \mathrm{m}$ and $0.16 \mu \mathrm{m}$, respectively, and the 


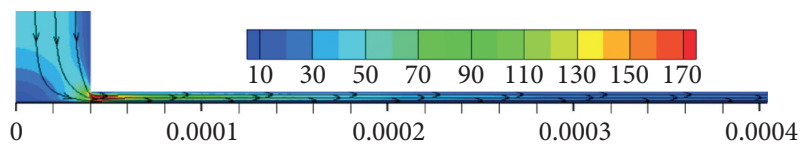

(a)

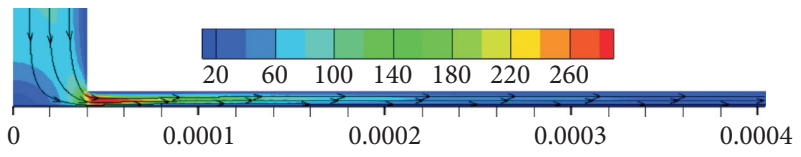

(c)

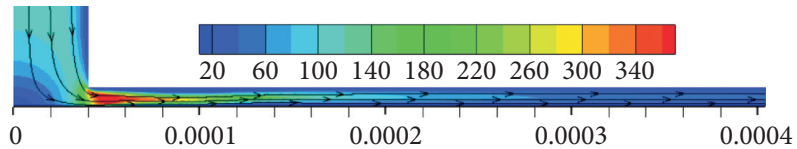

(e)

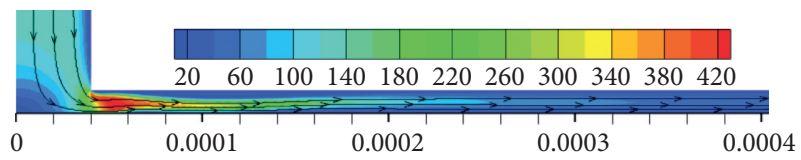

(g)

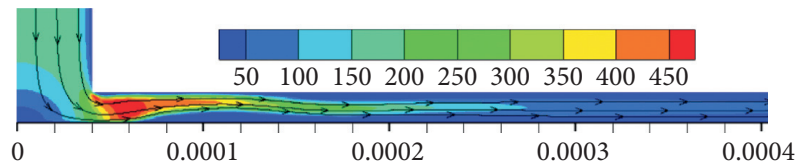

(i)

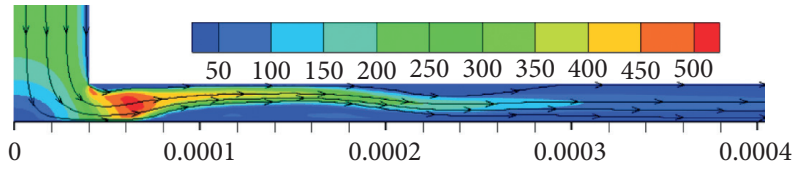

(k)

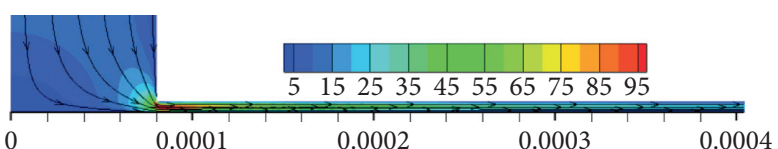

(b)

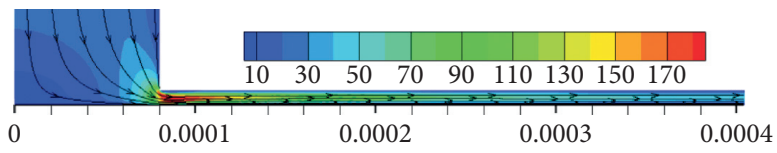

(d)

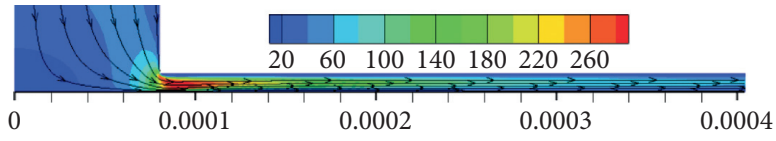

(f)

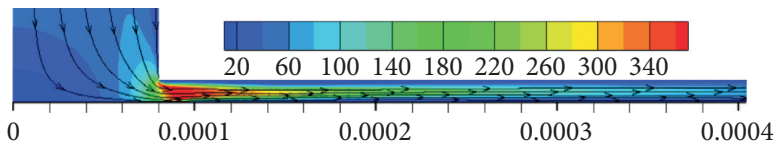

(h)

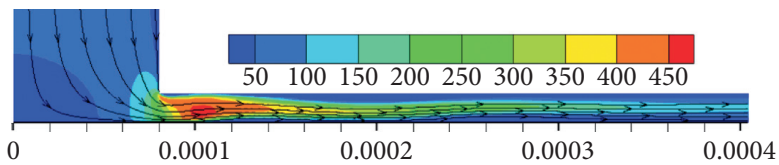

(j)

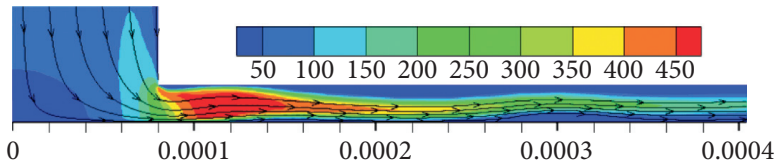

(1)

Figure 12: Cloud chart of the velocity of the gas film at different $h$. (a) $d=0.08 \mathrm{~mm}, h=6 \mu \mathrm{m}$, (b) $d=0.16 \mathrm{~mm}, h=6 \mu \mathrm{m},(\mathrm{c}) d=0.08 \mathrm{~mm}$, $h=8 \mu \mathrm{m}$, (d) $d=0.16 \mathrm{~mm}, h=8 \mu \mathrm{m}$, (e) $d=0.08 \mathrm{~mm}, h=10 \mu \mathrm{m}$, (f) $d=0.16 \mathrm{~mm}, h=10 \mu \mathrm{m},(\mathrm{g}) d=0.08 \mathrm{~mm}, h=12 \mu \mathrm{m},(\mathrm{h}) d=0.16 \mathrm{~mm}$, $h=12 \mu \mathrm{m}$, (i) $d=0.08 \mathrm{~mm}, h=16 \mu \mathrm{m}$, (j) $d=0.16 \mathrm{~mm}, h=16 \mu \mathrm{m},(\mathrm{k}) d=0.08 \mathrm{~mm}, h=20 \mu \mathrm{m}$, and (l) $d=0.16 \mathrm{~mm}, h=20 \mu \mathrm{m}$.

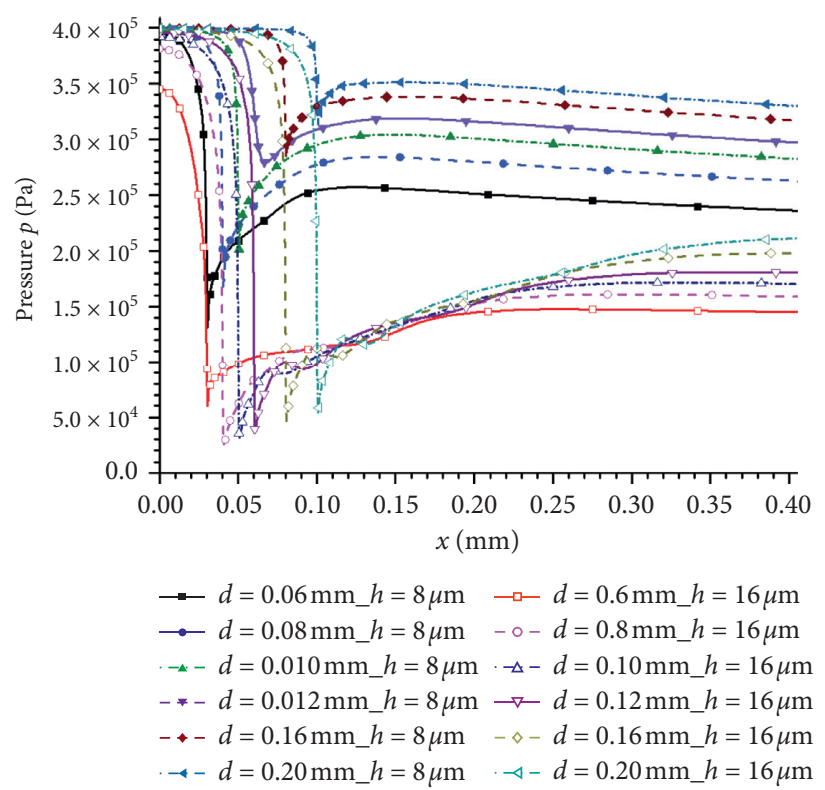

Figure 13: Curves $D 1$ of the pressure of the gas film at different $d$. 


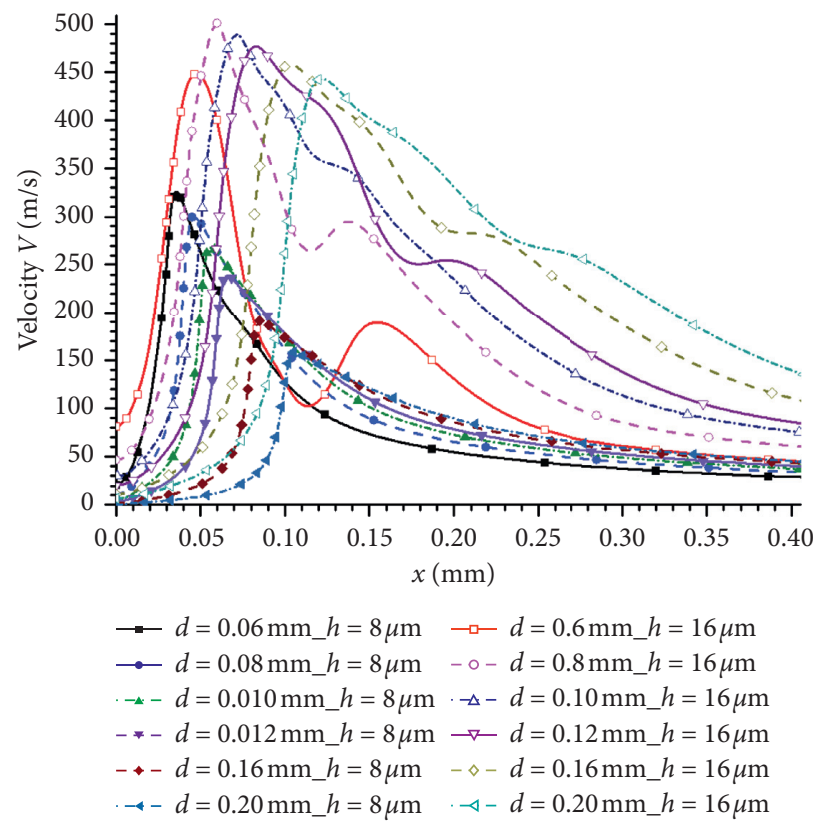

Figure 14: Curves D2 of the velocity of the gas film at different $d$.

diameter $d$ of the orifice is $0.06 \mathrm{~mm}, 0.08 \mathrm{~mm}, 0.10 \mathrm{~mm}$, $0.12 \mathrm{~mm}, 0.16 \mathrm{~mm}$, and $0.20 \mathrm{~mm}$, respectively; the cloud chart of the velocity $V$ of the gas film flow field at the outlet of the orifice of aerostatic bearing is shown in Figure 15. The unit of the horizontal ordinate in Figure 15 is meters, and the unit of the velocity of the cloud chart in Figure 15 is meters per second.

Through the analysis from Figures 7-15 and a large number of numerical calculation and analysis by the author's research group, it can be basically concluded that when the gas supply pressure $p_{s}$ of the aerostatic bearing is $0.4 \mathrm{MPa}$, the ratio $\theta$ between the gas film clearance $h$ and the diameter $d$ of the orifice is basically $1: 10$ (the critical ratio is $\theta_{0}$ ) and the gas film flow field begins to fluctuate in different degrees. When the diameter $d$ of the orifice of the aerostatic bearing is less than or equal to $0.14 \mathrm{~mm}$, the gas film flow field is relatively stable and smooth if $\theta$ is less than $1: 10$, the flow field begins to fluctuate in different degrees if $\theta$ is greater than $1: 10$, and the flow field will fluctuate more with the increase of $\theta$. When the diameter $d$ of the orifice of the aerostatic bearing is larger than $0.14 \mathrm{~mm}$, the corresponding critical ratio $\theta_{0}$ will gradually decrease.

\section{Experimental Analysis}

Based on the numerical calculation and the analysis of the flow field of the aerostatic bearing, a performance test platform for aerostatic bearings has been developed by combining the structure and performance parameters of aerostatic bearings. The relevant parameters, with the gas supply pressure $p_{s}$, the bearing capacity $W$, and the gas film clearance $h$ of the aerostatic bearing, are tested, analyzed, and studied, and the overall structure of the experimental performance test platform for the aerostatic bearing is shown in Figure 16.

In Figure 16, the whole test device platform is mainly composed of the loading device, the testing device, the gas supply device, the vibration isolation device, and the platform support device. The loading device and the testing device are installed in the mouth-shaped granite frame 1 , the mouth-shaped granite frame 1 is placed on the granite base 15 , and the vibration isolator 14 is arranged between the mouth-shaped granite frame 1 and the granite base 15 . The loading cylinder 4 , the main component of the loading device, is fixed in the mouth-shaped granite frame 1 through the cylinder base 2 and the bolt 3 . The static force applying rod 5 and the steel ball 9 are aligned and contacted with the tested aerostatic bearing 10 . The continuous loading of the tested aerostatic bearing 10 is realized by adjusting the inlet and outlet pressure of the loading cylinder 4; The bearing platform 13 is fixed on the mouth-shaped granite frame 1, the force sensor 12 is installed on the bearing platform 13, and the force sensor 12 is connected with the pressure test plate 11. The working surface of the tested aerostatic bearing 10 is opposite to the working plane of the pressure test plate 11. According to the test requirements, the gas supply pressure $p_{s}$ of the gas inlet of the tested aerostatic bearing 10 is adjusted, and the bearing capacity $W$ of the tested aerostatic bearing 10 is tested by the force sensor 12 . The displacement sensor 16 is fixed to the mouth-shaped granite frame 1 through the support bracket 17, the probe of the displacement sensor 16 is aligned with the back of the tested aerostatic bearing 10, and the gas film clearance $h$ of the tested aerostatic bearing 10 is measured. The bracket 6 , the connecting frame 7 , and the connecting plate 8 on the platform are used for the later dynamic test of the aerostatic bearing. Through the performance test platform of the 


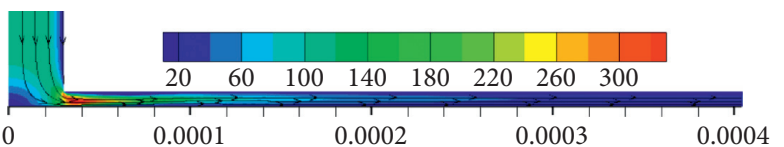

(a)

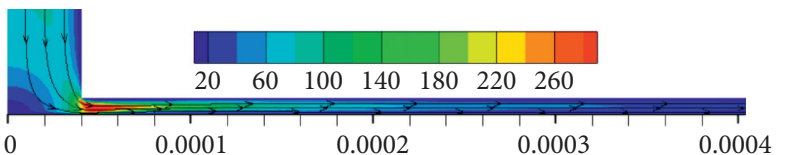

(c)

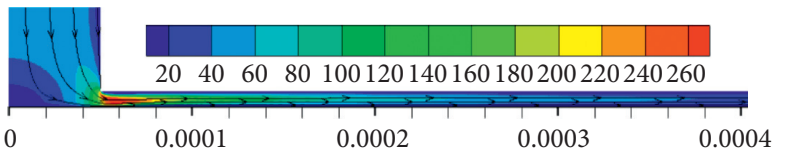

(e)

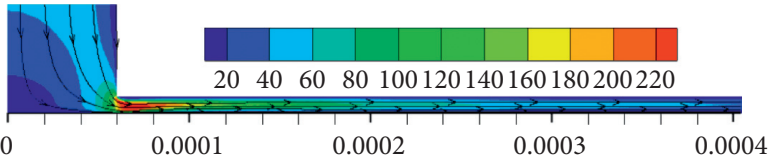

(g)

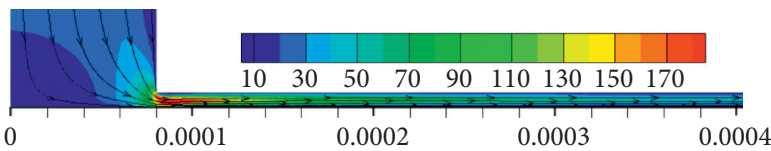

(i)

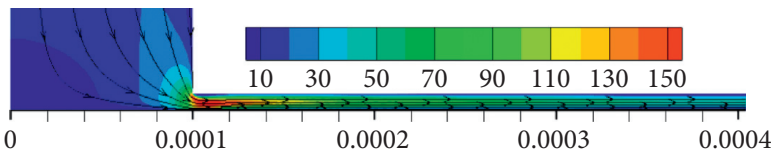

$(\mathrm{k})$

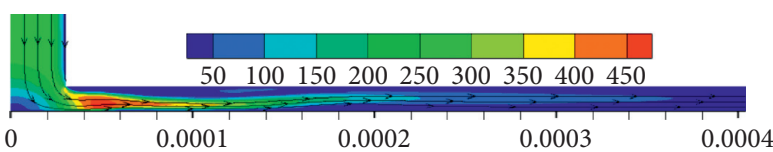

(b)

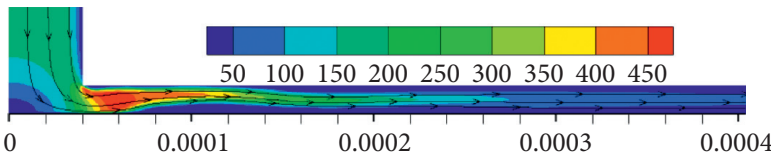

(d)

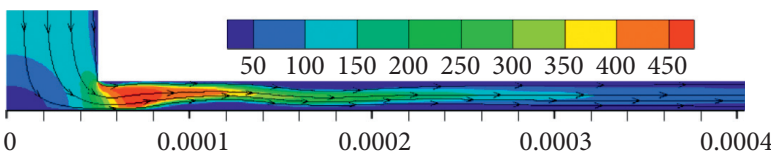

(f)

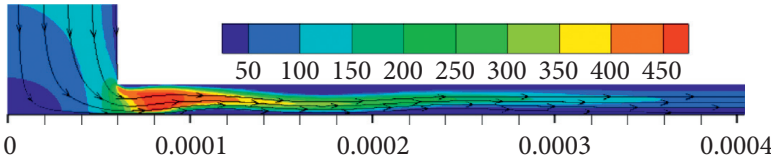

(h)

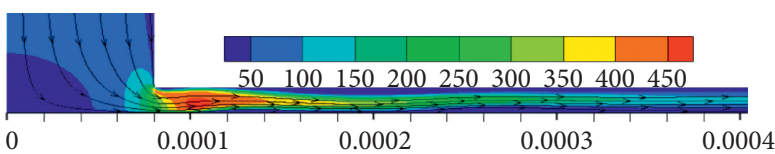

(j)

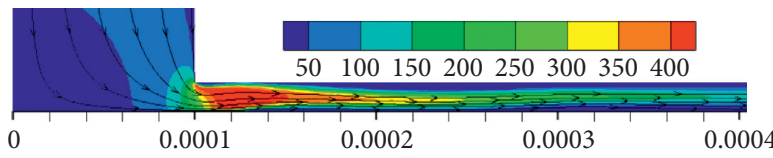

(1)

Figure 15: Cloud chart of the velocity of the gas film at different $d$. (a) $d=0.06 \mathrm{~mm}, h=8 \mu \mathrm{m}$, (b) $d=0.06 \mathrm{~mm}, h=16 \mu \mathrm{m}$, (c) $d=0.08 \mathrm{~mm}$, $h=8 \mu \mathrm{m}$, (d) $d=0.08 \mathrm{~mm}, h=16 \mu \mathrm{m}$ (e) $d=0.10 \mathrm{~mm}, h=8 \mu \mathrm{m}$, (f) $d=0.10 \mathrm{~mm}, h=16 \mu \mathrm{m},(\mathrm{g}) d=0.12 \mathrm{~mm}, h=8 \mu \mathrm{m},(\mathrm{h}) d=0.12 \mathrm{~mm}$, $h=16 \mu \mathrm{m}$, (i) $d=0.16 \mathrm{~mm}, h=8 \mu \mathrm{m}$, (j) $d=0.16 \mathrm{~mm}, h=16 \mu \mathrm{m}$, (k) $d=0.20 \mathrm{~mm}, h=8 \mu \mathrm{m}$, and (l) $d=0.20 \mathrm{~mm}, h=16 \mu \mathrm{m}$.

aerostatic bearing, the gas supply pressure $p_{s}$, the bearing capacity $W$, the gas film clearance $h$, and other related parameters of the test specimen for the aerostatic bearing can be tested, respectively.

The diagram of the physical device for the test platform is shown in Figure 17. The test platform is supported by the base of granite frame, and the loading cylinder is used to load the tested aerostatic bearing. By adjusting the external pressure difference, the tested aerostatic bearing can be continuously loaded, The gas supply pipeline is applied to supply high-pressure gas to the tested aerostatic bearing, and the required gas supply pressure of the tested aerostatic bearing can be adjusted and set by the pressure stabilizing valve connected to the gas supply pipeline. Through the displacement sensor and the force measuring sensor, the gas film clearance and load of the tested aerostatic bearing are tested, the data of which are displayed and recorded on the displacement display instrument and the force measuring display instrument. The gas film clearance of the tested aerostatic bearing in the test platform is tested by using a DGS-6C digital inductance micrometer and a DGC-8ZG/D inductance displacement sensor probe, and the measurement range is $100 \mu \mathrm{m}$ with a resolution of $0.1 \mu \mathrm{m}$. The bearing capacity of the tested bearing specimens is measured by using an LH-S10D force sensor with a resolution of $0.1 \mathrm{~N}$ and a force range of $0-1000 \mathrm{~N}$.

The tested aerostatic bearing with a diameter of $30 \mathrm{~mm}$ is selected as the test sample in this paper, the diameter of the orifice is $d=0.2 \mathrm{~mm}$, the external environment pressure $P_{a}$ is $0.1 \mathrm{MPa}$, the absolute temperature $T$ is $288 \mathrm{~K}$, and gas supply pressures $p_{s}$ are $0.4 \mathrm{MPa}, 0.5 \mathrm{MPa}$, and $0.6 \mathrm{MPa}$, respectively. The numerical calculation and experimental test results of the aerostatic bearing are compared and analyzed. The numerical calculation and experimental test results are shown in Figure 18.

It can be seen from Figure 18 that the bearing capacity $W$ of the tested aerostatic bearing decreases gradually with the increase of the gas film clearance $h$ under each gas supply pressure $p_{s}$. Under the same gas film clearance $h$, the bearing capacity $W$ of the aerostatic bearing increases with the increase of gas supply pressure $p_{s}$. With the increase of the gas film clearance $h$ and under different gas supply pressures $p_{s}$, 


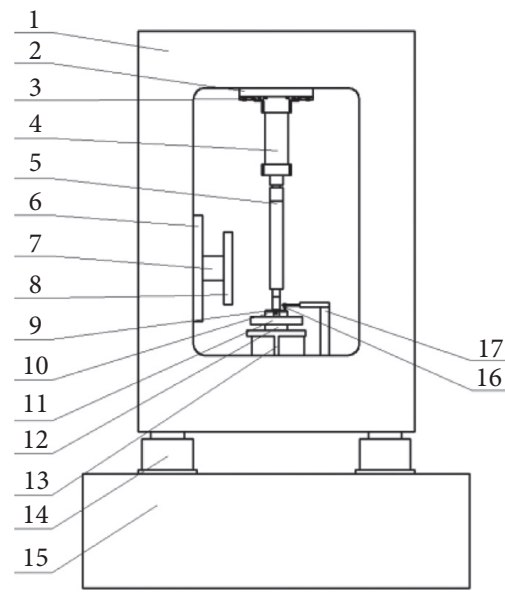

FIGURE 16: Schematic diagram of the overall structure of the test platform. (1) Mouth-shaped granite frame; (2) cylinder base; (3) bolt; (4) loading cylinder; (5) static force applying rod; (6) bracket; (7) connecting frame; (8) connecting plate; (9) steel ball; (10) tested aerostatic bearing; (11) pressure test plate; (12) force sensor; (13) bearing platform; (14) vibration isolator; (15) granite base; (16) displacement sensor; and (17) support bracket.

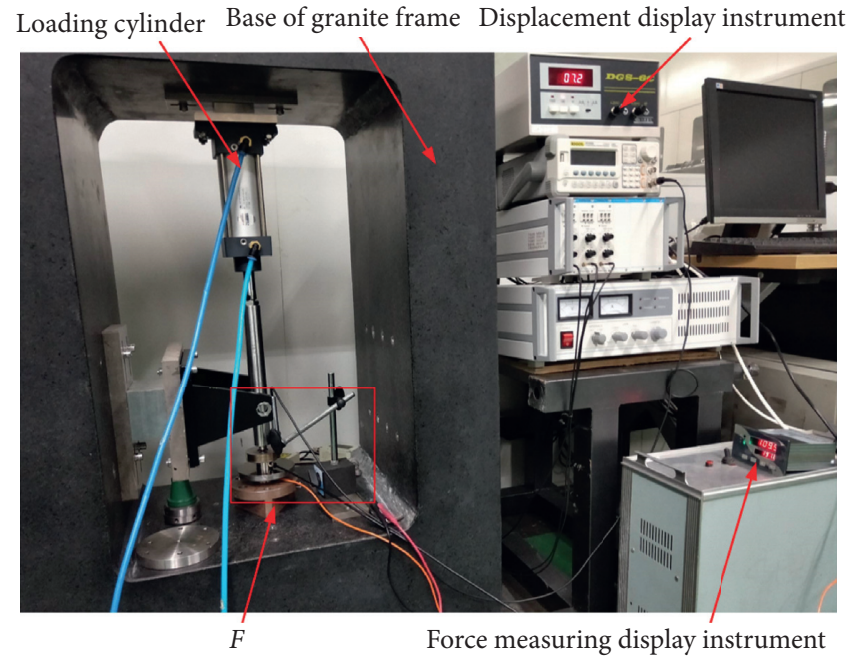

(a)

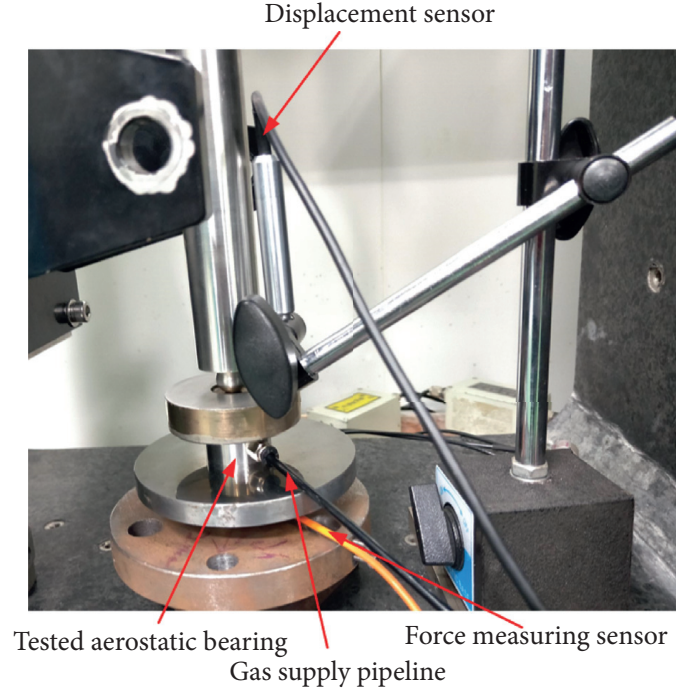

(b)

FIGURE 17: Diagram of the physical device for the test platform. (a) General drawing of the physical device; (b) partial enlarged drawing at $F$.

the difference of the bearing capacity $W$ of the aerostatic bearing decreases. The numerical results of the aerostatic bearing studied in this paper are consistent with the experimental results; nevertheless, there are some differences. When the gas film clearance $h$ is small, the bearing capacity $W$ of the tested aerostatic bearing is slightly larger or coincides with the numerical results. With the increase of gas film clearance $h$, the difference between the test results and the numerical results increases slightly. The experimental results are consistent with the numerical results, which verify the feasibility and correctness of the numerical results and numerical methods. 


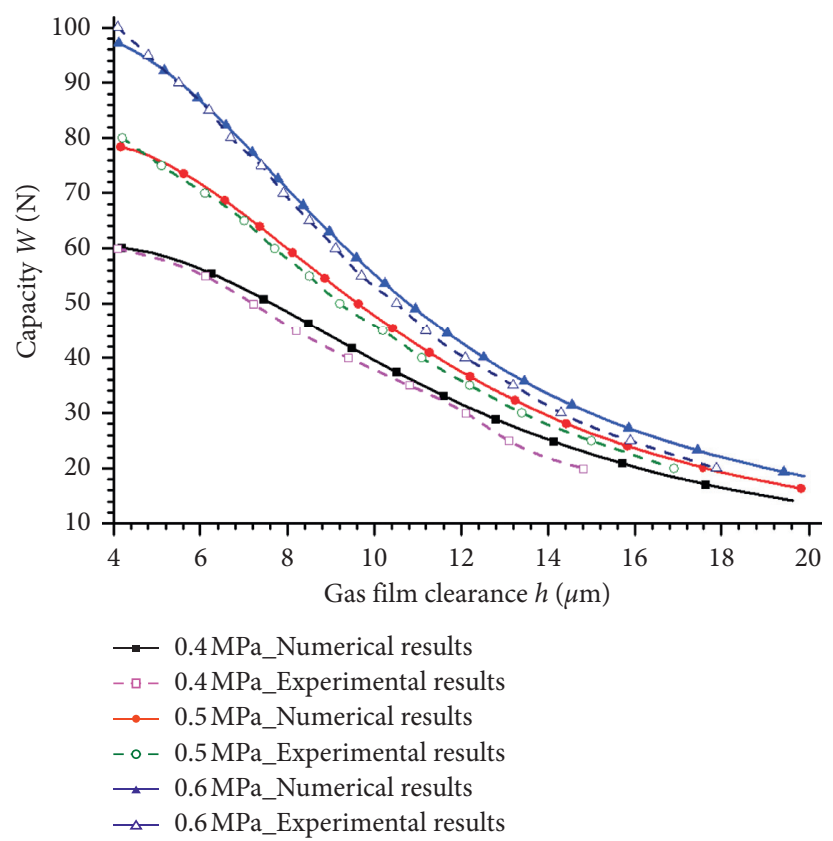

FIgURE 18: Curves of theoretical and experimental results of bearing capacity.

\section{Conclusions}

The influencing factors and regulars of the gas film flow field have been explored and studied at the outlet of the orifice of the aerostatic bearing. The large eddy simulation method has been used to calculate the N-S equation in the calculation area of the gas film flow field at the outlet of the orifice of the aerostatic bearing, and the overrelaxation iteration method has been used to solve the Reynolds equation in the other calculation areas, which has been proposed in this paper. The related factors affecting the gas film flow field have been discussed, and the relevant experimental tests of the bearing performance have been carried out. Under the matching of certain factors such as the supply pressure $p_{s}$, the film clearance $h$, and the orifice diameter $d$, the pressure distribution and velocity $V$ of the gas film flow field at the outlet of the orifice of the aerostatic bearing began to fluctuate in varying degrees. These may be the initial signal states for the transition of turbulence from the gas film flow field of the aerostatic bearing, which provide a good theoretical support and basis for further discussion of the transition lubrication mechanism between the laminar and the turbulent flow at the outlet of the orifice. The research and analysis of the gas film flow field at the outlet of the orifice of the aerostatic bearing have been carried out in this paper. The influence parameters, such as the air supply pressure $p_{s}$, the gas film clearance $h$, and orifice diameter $d$, on the gas film flow field lubrication support is further explored and revealed, which will greatly promote and improve the application and promotion of aerostatic bearings in the precision and ultraprecision machining equipment and measuring instruments.

\section{Nomenclature}

A: The area of the orifice, the symbol of the study area

$\bar{A}: \quad$ Multiple additional sublattice mode terms

$C_{0}$ : The coefficient of the nozzle

$d$ : The diameter of the orifice

$D$ : The overall diameter of the aerostatic bearing

D1: The diameter of the dotted line selected

E: The total internal energy of the unit mass fluid

$h$ : The gas film clearance

$H$ : The overall height of the aerostatic bearing

$i$ : The direction of Cartesian coordinates, the normal direction of the action surface

$j$ : The direction of Cartesian coordinates, the projection direction of force

K: $\quad$ The stiffness

$l$ : The length of the orifice

$p: \quad$ The gas film pressure

$p_{0}$ : The pressure at the outlet of the orifice

$p_{1}$ : The outlet interface pressure of the flow field

$p_{a}$ : The environment pressure

$p_{s}: \quad$ The gas supply pressure

$q_{i}$ : The heat flux density of heat conduction

Q: The gas mass flow

$Q_{\text {in }}$ : The flow of gas through the orifice into the gas film clearance

$Q_{\text {out }}$ : The flow of gas from the gas film clearance into the surrounding environment

$r$ : The polar radius in the polar coordinate system

$R: \quad$ The gas constant

$t$ : The time

$T_{w}$ : The wall temperature 
T: $\quad$ The temperature

$T_{0}$ : The gas supply temperature

$u_{i}$ : The velocity component in the $i$-direction in Cartesian coordinates

$u_{j}$ : The velocity component in the $j$-direction in Cartesian coordinates

$W$ : The bearing capacity

$x_{i}$ : The coordinates in the direction of $i$

$x_{j}$ : The coordinates in the direction of $j$

$y^{+}: \quad$ The resolution of the grid near the wall

$\Delta x 1$ : The horizontal grid spacing of the first layer along the $x$-direction

$\Delta z 1$ : The longitudinal grid spacing of each first layer along the $z$-direction

$\theta_{0}: \quad$ The critical ratio

$\theta$ : The polar angle in the polar coordinate system, the ratio between the gas film clearance $h$ and the orifice diameter $d$

$\rho: \quad$ The density of the gas

$\mu$ : The dynamic viscosity of the gas

$\kappa: \quad$ The gas insulation coefficient

$\tau_{w}: \quad$ Wall shear stress

$\sigma_{i j}$ : The element (component)of the viscous stress tensor

$\bar{\sigma}_{i j}$ : The molecular viscous stress with filtration speed and temperature as parameters

\section{Data Availability}

The data used to support the findings of this study are available from the corresponding author upon request.

\section{Conflicts of Interest}

The authors declare that they have no conflicts of interest.

\section{Acknowledgments}

This research was supported by the National Natural Science Foundation of China (51705390), Science and Technology Project of Weiyang District (201838), Key Laboratory Project of Shaanxi Province Education Department (19JS033), and Xi'an Technological University school-level fluid lubrication technology research and innovation team.

\section{References}

[1] J. Yuan, F. Zhang, Y. Dai et al., "Development research of science and technologies in ultra-precision machining field," Journal of Mechanical Engineering, vol. 46, no. 15, pp. 161-177, 2010.

[2] Z. Lu, J. Zhang, and B. Liu, "Research and analysis of the static characteristics of aerostatic bearings with a multihole integrated restrictor," Shock and Vibration, vol. 2020, Article ID 7426928, 11 pages, 2020.

[3] Y. Liang and Y. Sun, "Research status and outlook of ultraprecision machine tool," Journal of Harbin Institute of Technology, vol. 46, no. 5, pp. 28-39, 2014.

[4] X. Luo, K. Cheng, D. Webb, and F. Wardle, "Design of ultraprecision machine tools with applications to manufacture of miniature and micro components," Journal of Materials Processing Technology, vol. 167, no. 2-3, pp. 515-528, 2005.

[5] T. Li, Z. Chen, X. Ding et al., "Design of the aerostatic linear guideway with micro-structured surfaces for ultra precision machine tools," Journal of Mechanical Engineering, vol. 53, no. 3, pp. 193-200, 2017.

[6] X. Zhao, J. Zhang, H. Dong, Z. Fang, and J. Jun, "Numerical simulation and experimental study on the gas-solid coupling of the aerostatic thrust bearing with elastic equalizing pressure groove," Shock and Vibration, vol. 2017, Article ID 5091452, 11 pages, 2017.

[7] Y. Li, Y. Lin, H. Zhu et al., "Analysis of the micro self-vibration of aerostatic thrust bearing based on large eddy simulation," Journal of Mechanical Engineering, vol. 49, no. 13, pp. 56-62, 2013.

[8] J. Zhang, D. Zou, N. Ta, and Z. Rao, "Numerical research of pressure depression in aerostatic thrust bearing with inherent orifice," Tribology International, vol. 123, pp. 385-396, 2018.

[9] D. Chen, F. Zhang, and P. Fu, "Identification fluctuation of aerostatic guideway," Journal of Mechanical Engineering, vol. 46, no. 21, pp. 187-193, 2010.

[10] M. Zhang, Y. Zhu, and G. Duan, "Micro-vibration of ultraprecision gas bearing linear motion stage and its limitation," Manufacturing Technology \& Machine Tool, vol. 11, pp. 47-49, 2005.

[11] X. Chen, H. Chen, X. Luo, Y. Ye, Y. Hu, and J. Xu, “Air vortices and nano-vibration of aerostatic bearings," Tribology Letters, vol. 42, no. 2, pp. 179-183, 2011.

[12] H. Mori, "A theoretical investigation of pressure depression in externally pressurized gas-lubricated circular thrust bearings," Journal of Basic Engineering, vol. 83, no. 2, pp. 201-208, 1961.

[13] S. Yoshimoto, M. Yamamoto, and K. Toda, "Numerical calculations of pressure distribution in the bearing clearance of circular aerostatic thrust bearings with a single air supply inlet," Journal of Tribology, vol. 129, no. 2, pp. 384-390, 2007.

[14] M. E. Eleshaky, "CFD investigation of pressure depressions in aerostatic circular thrust bearings," Tribology International, vol. 42, no. 7, pp. 1108-1117, 2009.

[15] M. Miyatake and S. Yoshimoto, "Numerical investigation of static and dynamic characteristics of aerostatic thrust bearings with small feed holes," Tribology International, vol. 43, no. 8, pp. 1353-1359, 2010.

[16] X.-D. Chen and X.-M. He, "The effect of the recess shape on performance analysis of the gas-lubricated bearing in optical lithography," Tribology International, vol. 39, no. 11, pp. 1336-1341, 2006.

[17] T. Aoyama, Y. Kakinuma, and Y. Kobayashi, "Numerical and experimental analysis for the small vibration of aerostatic guideways," CIRP Annals, vol. 55, no. 1, pp. 419-422, 1, 2006.

[18] X. Chen, H. Chen, J. Zhu, and W. Jiang, "Vortex suppression and nano-vibration reduction of aerostatic bearings by arrayed microhole restrictors," Journal of Vibration and Control, vol. 23, no. 5, pp. 842-852, 2017.

[19] J. Zhu, H. Chen, and X. Chen, "Large eddy simulation of vortex shedding and pressure fluctuation in aerostatic bearings," Journal of Fluids and Structures, vol. 40, pp. 42-51, 2013.

[20] Q. Chen, B. Chen, and L. Cai, "Effect of equalizing grove on small vibration of aerostatic bearings," Optics and Precision Engineering, vol. 22, no. 12, pp. 3354-3359, 2014.

[21] X. Liu, Z. Lu, J. A. Zhang, B. Liu, Y. Cao, and X. Qian, "The self-lubricating behavior and evolution mechanisms of the surface microporous friction interface of M50-(Sn-Ag- $\mathrm{Cu})$ material," Journal of Materials Research and Technology, vol. 9, no. 4, pp. 8207-8220, 2020. 
[22] F. Al-Bender, "On the modelling of the dynamic characteristics of aerostatic bearing films: from stability analysis to active compensation," Precision Engineering, vol. 33, no. 2, pp. 117-126, 2009.

[23] D. Fu, Y. Ma, X. Li et al., "Direct numerical simulation of compressible turbulence," Science Press, vol. 11, pp. 201-206, 2010

[24] Z. Zhang, G. Cui, and C. Xu, "Theory and application of numerical simulation of turbulent large eddy," Tsinghua University Press, vol. 1, pp. 54-75, 2008. 